
\title{
3 Research Square \\ Error Identification Method of Five-Axis Machine Tool Based on Sample Test Method
}

\author{
xuehu Lv \\ Shandong University of Technology \\ qianjian Guo ( $\square$ guoqj_xs@163.com ) \\ Shandong University of Technology \\ wei Yuan \\ Shandong University of Technology \\ wenhua Wang \\ Shandong University of Technology \\ yuqi Zhu \\ Shandong University of Technology \\ haotian Wang \\ Shandong University of Technology
}

\section{Research Article}

Keywords: Five-axis machine tool, Sample test method, Positioning error, Error model

Posted Date: June 17th, 2021

DOI: https://doi.org/10.21203/rs.3.rs-604420/v1

License: (c) (i) This work is licensed under a Creative Commons Attribution 4.0 International License. Read Full License

Version of Record: A version of this preprint was published at The International Journal of Advanced Manufacturing Technology on January 28th, 2022. See the published version at https://doi.org/10.1007/s00170-022-08779-z. 


\section{Abstract}

In order to improve the predictive ability of the error model of the five-axis machine tool, an indirect error measurement (IEM) method of the five-axis machine tool based on the sample test method was proposed, and the optimized design of the stepped axis sample was completed. By inversely calculating the spatial error model of the machine tool, the function analysis relationship between the sample machining error and different error terms of the machine tool was established, and then the dynamic errors of the machine tool in different machining states were obtained. The reliability and practical effects of the method was verified through experiments. The results showed that the proposed IEM method was in good agreement with the laser measurement method. The predictive ability of the error model of the five-axis machine tool can be improved by using the IEM method, thereby more machining accuracy of the machine tool will be ensured.

\section{Introduction}

The precision and productivity of user demand for the five-axis machining of complex workpiece surfaces is gradually increasing [1]. Accuracy is a crucial consideration for evaluating the capability of multi-axis machine tools. Geometric error is one of the key contributors to the overall errors of machine tools. Geometric error compensation is currently a hot topic of research at home and abroad $[2,3]$. There are two main methods for measuring errors in 5-axis machines as the direct measurement and the indirect measurement. Direct measurement means to measure the single error of the five-axis machine tool [4]. Due to too many single error of the five-axis machine tool, direct measurement efficiency is low. Indirect measurement is also known as error identification [5]. By detecting the position of the tool tip and separating the single error by using the machine tool motion model, multiple errors can be obtained in one measurement and the measurement efficiency has been greatly improved.

The traditional indirect measurement methods mainly include ball bar test, laser measurement, plane orthogonal grating method and R-Test method $[6,7]$. These methods mainly have two types of problems. First, the measurement equipment is expensive and the operation process is complicated and timeconsuming, which cannot truly reflect the motion error of the actual machine tool processing. Second, the objective of various measurement methods is to measure quickly and effectively, without considering the actual machining state, and the measurement results are static. In engineering practice, there is a coupling relationship in systems, and the static error can hardly solve the practical problems.

Sample test method [8] can solve the main problems existing in the traditional indirect measurement method and better simulate the actual machining process. As shown in Fig. 1, such method indirectly measures the 5-axis machine tool error by simulating or actual cutting of different samples. Due to the full consideration of the cutting condition of the machine tool, the measurement result is dynamic and the measurement accuracy is higher. In this paper, the dynamic error measurement method of five-axis machine tool was studied on the basis of considering the cutting state. 
The dynamic error measurement method of five-axis machine tool was studied on the premise of considering the cutting state. In order to measure the machine tool error in the actual cutting state, an indirect method of IEM of five-axis machine tool based on the sample machining was proposed based on the sample design. Through the actual cutting of the sample, the dynamic error of the five-axis machine tool was separated and identified indirectly by the actual cutting of the sample.

\section{Design Of Stepped Shaft Prototype}

The prototype testing method is still in the research stage, and three problems exist. First, the prototype design lacks a uniform standard, such as the prototypes designed by Erkan [9] and Liebrich et al. [10], and the spatial error of the five-axis machine can be obtained by measuring the main ball spacing shown in Fig. 1(b). Keaveney [11] and Kato [12] designed a circular table prototype, and by performing simulated cutting, the accuracy of machine motion can be checked. However, there is no optimal prototype structure that can characterize the accuracy of a 5 -axis machine. Second, existing tests are still mainly simulating the tool trajectory and are still performed in the cold and no-cut condition of the machine. Although Ibaraki [13] and Hong [14] performed actual machining of sample parts, they did not consider the effect of the cutting state on the dynamic error pattern of the 5-axis machine. Third, lack of sensitivity of the sample testing process to the machine error sources, which makes it difficult to separate and identify the machine errors. Ibaraki et al. [15] and Mchichi et al. [16] have explored this problem, but have not obtained an ideal identification model.

To test the prototype machining of a 5-axis machine, the stepped-axis prototype was designed as shown in Fig. 2 based on the machine error measurement method in circular trajectory motion.

In order to optimize the selection of the sample machining parameters, the author conducted an orthogonal experimental design. This experiment is a four-factor experiment. According to the main factors affecting the machining error (spindle speed, feed, radial depth of cut and axial depth of cut), $L_{9}$ $\left(3^{4}\right)$ table is selected for the orthogonal design, and the material is 45 steel as an example. During the machining of the sample part, the radial depth of cut $A_{\mathrm{e}}$ was selected as $20 \mathrm{~mm}, 40 \mathrm{~mm}$ and $60 \mathrm{~mm}$, and the axial depth of cut $A_{\mathrm{p}}$ was set as $0.5 \mathrm{~mm}, 1.0 \mathrm{~mm}$ and $1.5 \mathrm{~mm}$, and the cutting speed and feed were set with reference to the tool description, and the preliminary experimental scheme is shown in Table 1. After completing a set of experiments with 45 steel samples, experiments were conducted in the same way with Inconel 600 and 6066 aluminum alloys to obtain the optimal processing parameters for different materials.

The integrated error model is the difference between the actual and ideal positions of the tool forming point in the workpiece coordinate system $P_{\mathrm{w}^{-}} P_{\text {wideal }}$. The integrated error model of a five-axis machine along the $X$-axis was expressed in Eq. (1). 
Table 1

Sample processing experiment plan

\begin{tabular}{|llllll|}
\hline $\begin{array}{l}\text { serial } \\
\text { number }\end{array}$ & $\begin{array}{l}\text { Factor A Feed } \\
\text { quantity(mm/min) }\end{array}$ & $\begin{array}{l}\text { Factor B } \\
\text { Spindle } \\
\text { speed(r/min) }\end{array}$ & $\begin{array}{l}\text { Factor C Radial } \\
\text { cutting } \\
\text { depth(mm) }\end{array}$ & $\begin{array}{l}\text { Factor D axial } \\
\text { cutting } \\
\text { depth(mm) }\end{array}$ & $\begin{array}{l}\text { Error of } \\
\text { experimental } \\
\text { results(mm) }\end{array}$ \\
\hline 1 & 100 & 1000 & 20 & 0.5 & 0.0095 \\
\hline 2 & 100 & 1500 & 40 & 1.0 & 0.0087 \\
\hline 3 & 100 & 2000 & 60 & 1.5 & 0.0093 \\
\hline 4 & 150 & 1000 & 40 & 1.5 & 0.0085 \\
\hline 5 & 150 & 1500 & 60 & 0.5 & 0.0098 \\
\hline 7 & 150 & 2000 & 20 & 1.0 & 0.0086 \\
\hline 8 & 200 & 1000 & 60 & 1.0 & 0.0092 \\
\hline 9 & 200 & 1500 & 20 & 1.5 & 0.0082 \\
\hline$K_{1}$ & 0.092 & 2000 & 40 & 0.5 & 0.0081 \\
\hline$K_{2}$ & 0.090 & 0.091 & 0.088 & 0.091 & \\
\hline$K_{3}$ & 0.085 & 0.089 & 0.084 & 0.088 & \\
\hline$R$ & 0.007 & 0.087 & 0.094 & 0.087 & \\
\hline
\end{tabular}




$$
\Delta x=\sin \gamma \cos \alpha\left\{\begin{array}{l}
-C_{\alpha z} \cos \gamma+\sin \alpha \sin \gamma \\
+\varepsilon_{x C}(\gamma) \sin \alpha \cos \gamma+ \\
\varepsilon_{x A}(\alpha) \sin \alpha \cos \gamma- \\
C_{\alpha z} \cos \alpha \cos \gamma+S_{c z} \mathrm{~g} \\
\cos \alpha \sin \gamma+\sin \alpha \cos \gamma \\
+\sin \alpha \cos \gamma\left[\varepsilon_{z}(z)-\right. \\
\left.\varepsilon_{z}(x)-\varepsilon_{z}(y)\right]-\cos \alpha \mathrm{g} \\
{\left[\varepsilon_{y}(z)-\varepsilon_{y}(x)-\varepsilon_{y}(y)\right.} \\
\left.+\varepsilon_{y S}\right]
\end{array}\right\}+\cos \alpha \cos \gamma\left\{\begin{array}{l}
-\sin \alpha \sin \gamma\left[\varepsilon_{z}(z)-\varepsilon_{z}(x)\right. \\
\left.-\varepsilon_{z}(y)\right]+C_{\alpha \varepsilon} \sin \gamma+\sin \alpha \mathrm{g} \\
\cos \gamma-\varepsilon_{z C}(\gamma) \sin \alpha \sin \gamma+ \\
\varepsilon_{x A}(\alpha) \cos \alpha \cos \gamma+S_{c z} \mathrm{~g} \\
\cos \alpha \cos \gamma+C_{c e} \cos \alpha \sin \gamma \\
+\cos \alpha\left[\varepsilon_{x}(z)-\varepsilon_{x}(x)-\right. \\
\left.\varepsilon_{x}(y)+\varepsilon_{x S}\right]
\end{array}\right\}
$$

$$
-\sin \alpha\left\{\begin{array}{l}
\sin \alpha \sin \gamma\left[\varepsilon_{y}(z)-\varepsilon_{y}(x)-\varepsilon_{y}(y)\right. \\
\left.+\varepsilon_{y S}\right]-\sin \alpha \cos \gamma\left[\varepsilon_{x}(z)-\varepsilon_{x}(x)\right. \\
\left.-\varepsilon_{x}(y)+\varepsilon_{x S}\right]-S_{c \varepsilon} \sin \alpha+\cos \alpha \\
-\varepsilon_{x A}(\alpha) \sin \alpha
\end{array}\right\}
$$

where $\Delta x$ represents the deviation of the tool forming point along the $X$-axis in the workpiece coordinate system, $X, y$, and $z$ represent the position offset of $X, Y$, and $Z$ axes, respectively, $a, Y$ denote the directional shift of the $A$ and $C$ axes, respectively, the remaining parameters related to $C, S$, and $\varepsilon$, such as $C_{\mathrm{ae}}, S_{\mathrm{ce}}$ and $\varepsilon_{\mathrm{x}}(\mathrm{y})$, all represent different error terms of the five-axis machine.

As can be seen from Eq. (1), after establishing a comprehensive error model, the mathematical relationship between the machining error of the sample and the error term of the machine tool is determined. The $x, y, z$ and $a$ and $y$ in Eq. (1) are regarded as known, and $\Delta x$ can be obtained by sample machining error. By inverting Eq. (1), relevant error terms of the five-axis machine tool can be indirectly identified.

In order to obtain the $x, y, z$ and $a, y$ values required to solve Eq. (1), the moving and rotating axis offsets of the five-axis machine are investigated in this paper. During machining, the $X, Y$ and $Z$ axis offsets are determined according to the spatial position of the forming point, and the number of offset pairs corresponds to the number of measurement points, which is determined according to the unknown quantity of the equation. Different from moving axes, there is no theoretical basis for the biasing of two rotating axes $\mathrm{A}$ and $\mathrm{C}$, so the biasing of two rotating axes $\mathrm{A}$ and $\mathrm{C}$ is mainly designed, and the specific scheme is shown in Fig. 3.

According to the analytical function between the machining error of the sample and the error of the 5-axis machine, different machining trajectories of the sample are determined, and the bias combinations of $A$ and $\mathrm{C}$ axes are initially designed according to the different machining trajectories. On this basis, the Jacobi matrix of the error identification model is solved by optimizing the design and simulation 
processing of the $\mathrm{A}$ and $\mathrm{C}$ axis biases, and determining whether its condition number is reduced. If the number of conditions decreases, it means that the bias combination is good for machine error identification, otherwise, the bias combination should be deleted and the simulation process of the next bias combination should be optimized. The above process is repeated until the optimal $\mathrm{A}$ and $\mathrm{C}$ axis bias combination is finally determined.

Since the actual coordinates are measured by the coordinate measuring machine (CMM), the obtained coordinate values are relative to the CMM coordinate system and the $\Delta x$ in Eq. (1) is not the actual machining error of the sample. In order to obtain the actual coordinate values of the sample in the workpiece coordinate system, the spatial posture model between the coordinate system of the measuring machine and the workpiece coordinate system is established. The actual coordinates of the sample in the workpiece coordinate system are obtained and compared with its theoretical coordinates to obtain the required $\Delta x$.

\section{Experimental Verification}

The IEM of five-axis computer numerical control (CNC) machine tools verifies the feasibility and advancement of the indirect measurement method. Machining tests are performed on the prototype parts of the application design, and the machining errors of the prototype parts are measured, and the different error terms of the five-axis CNC machine tools are indirectly separated according to the measurement results. Meanwhile, the relevant error terms of the five-axis machine were measured directly to compare the difference between the direct and indirect measurement results and to verify the advancement of the indirect measurement method, and the measurement scheme is shown in Fig. 4.

The prototype machining test is performed on a 5-axis CNC machine, and then the prototype machining error is measured on a coordinate measuring machine, and the indirect measurement method of machine tool dynamic error based on the prototype machining is applied to indirectly separate and identify the machine tool related error terms with a laser interferometer. Meanwhile, direct measurements are performed on the error terms related to the machine tool. Then, the results of the sample measurements and the direct measurements are compared and the results are shown in Fig. 5.

As can be seen from Fig. 5, the difference between the measurement results of the two methods for the rotational axis $\mathrm{A}$-axis angular positioning error $\varepsilon \leq 0.0075^{\circ}$, and the difference between the measurement results of $C$-axis $\varepsilon \leq 0.0082^{\circ}$, it can be seen that there is not much difference between the identification results of the two methods. The positioning errors of $X$-axis, $Y$-axis and $Z$-axis of the machine tool are measured directly by laser interferometer, and then measured by indirect measurement method. The results of the two methods are shown in Fig. 6 , and it can be seen that the measurement results of the two methods match well, so the indirect measurement method is feasible in the measurement of the errors of the five-axis machine tool.

\section{Conclusion}


An IEM method of five-axis machine tool error based on the sample test method is proposed to indirectly measure the dynamic error of a five-axis machine tool by inverting the spatial error model of the machine tool and establishing the analytic function between the sample machining error and different error terms of the machine tool. The method has the following characteristics, the method is inexpensive and simple to operate, the results of the measured machine tool errors are dynamic and the measurement accuracy is high. An IEM method of 5-axis machine tool error based on sample test method can measure the dynamic error of machine tool more easily and improve the prediction ability of error model in actual manufacturing process.

\section{Declarations}

Acknowledgements: This work has been partly supported by Key R\&D project of Shandong Province (2019GGX104081, 2019GGX104033), National Natural Science Foundation of China (No. 51805299), Shandong Province's Key Support Regions Introducing Urgently Needed Talent Projects, and Young Innovative Talents Introduction and Training Program Project of Shandong Provincial Department of Education.

Availability of data and material: Not applicable.

Code availability: Not applicable.

Author contribution: Not applicable.

Funding:National Natural Science Foundation of China (No. 51805299), Key R\&D project of Shandong Province (2019GGX104081, 2019GGX104033), Shandong Province's Key Support Regions Introducing Urgently Needed Talent Projects, and Young Innovative Talents Introduction and Training Program Project of Shandong Provincial Department of Education.

Conflict of interest: The authors declare no competing interests.

\section{References}

1. V. Kvrgic, Z. Dimic, V. Cvijanovic, D. Ilic, M. Bucan (2012) A control algorithm for a vertical five-axis turning centre. The International Journal of Advanced Manufacturing Technology 61(5):569-584. https://doi.org/10.1007/s00170-011-3737-0

2. G. Cui, Y. Lu, D. Gao, Y. Yao (2012) A novel error compensation implementing strategy and realizing on Siemens 840D CNC systems. The International Journal of Advanced Manufacturing Technology 61(5):595-608. https://doi.org/10.1007/s00170-011-3747-y

3. J. Du, X.-g. Yan, X.-t. Tian (2012) The avoidance of cutter gouging in five-axis machining with a filletend milling cutter. The International Journal of Advanced Manufacturing Technology 62(1):89-97. https://doi.org/10.1007/s00170-011-3779-3 
4. Z. He, J. Fu, L. Zhang, X. Yao (2015) A new error measurement method to identify all six error parameters of a rotational axis of a machine tool. International Journal of Machine Tools and Manufacture 88:1-8. https://doi.org/10.1016/j.jmmachtools.2014.07.009

5. S.S. Makhanov (2010) Adaptable geometric patterns for five-axis machining: a survey. The International Journal of Advanced Manufacturing Technology 47(9):11671208. https://doi.org/10.1007/s00170-009-2244-z

6. H. Schwenke, W. Knapp (2008) H. Haitjema, A. Weckenmann, R. Schmitt, F. Delbressine, Geometric error measurement and compensation of machines-An update. CIRP Annals 57(2):660-675. https://doi.org/10.1016/j.cirp.2008.09.008

7. S. Weikert (2004) R-Test, a New Device for Accuracy Measurements on Five Axis Machine Tools. CIRP Annals 53(1):429-432. https://doi.org/10.1016/S0007-8506(07)60732-X

8. V. Alessandro, C. Gianni, S. Antonio (2015) Erratum to "Axis geometrical errors analysis through a performance test to evaluate kinematic error in a five axis tilting-rotary table machine tool" [Precis. Eng. 39 (2015) 224-233]. Precision Engineering 40:334. https://doi.org/10.1016/j.precisioneng.2014.12.003

9. T. Erkan, J.R.R. Mayer, Y. Dupont (2011) Volumetric distortion assessment of a five-axis machine by probing a 3D reconfigurable uncalibrated master ball artefact. Precision Engineering 35(1):116-125. https://doi.org/10.1016/j.precisioneng.2010.08.003

10. T. Liebrich, B. Bringmann, W. Knapp (2009) Calibration of a 3D-ball plate. Precision Engineering 33(1):1-6. https://doi.org/10.1016/j.precisioneng.2008.02.003

11. S. Keaveney, P. Connolly, E. Ahearne, G. Byrne (2014) Investigation of a Multi-Cone Variant of the Standard Cone Frustum Test for 5-Axis Machine Tools. Procedia CIRP 14:317322. https://doi.org/10.1016/j.procir.2014.03.038

12. N. Kato, M. Tsutsumi, R. Sato (2013) Analysis of circular trajectory equivalent to cone-frustum milling in five-axis machining centers using motion simulator. International Journal of Machine Tools and Manufacture 64:1-11. https://doi.org/10.1016/j.jjmachtools.2012.07.013

13. S. Ibaraki, Y. Ota (2014) A Machining Test to Evaluate Geometric Errors of Five-axis Machine Tools with its Application to Thermal Deformation Test. Procedia CIRP 14:323-328. https://doi.org/10.1016/j.procir.2014.03.109

14. C. Hong, S. Ibaraki, A. Matsubara (2011) Influence of position-dependent geometric errors of rotary axes on a machining test of cone frustum by five-axis machine tools. Precision Engineering 35(1):111. https://doi.org/10.1016/j.precisioneng.2010.09.004

15. S. Ibaraki, M. Sawada, A. Matsubara, T. Matsushita (2009) Machining tests to identify kinematic errors on five-axis machine tools. Precision Engineering 34(3):387-398. https://doi.org/10.1016/j.precisioneng.2009.09.007

16. N.A. McHichi, J.R.R. Mayer (2014) Axis Location Errors and Error Motions Calibration for a Five-axis Machine Tool Using the SAMBA Method. Procedia CIRP 14:305-310. https://doi.org/10.1016/j.procir.2014.03.088 


\section{Figures}

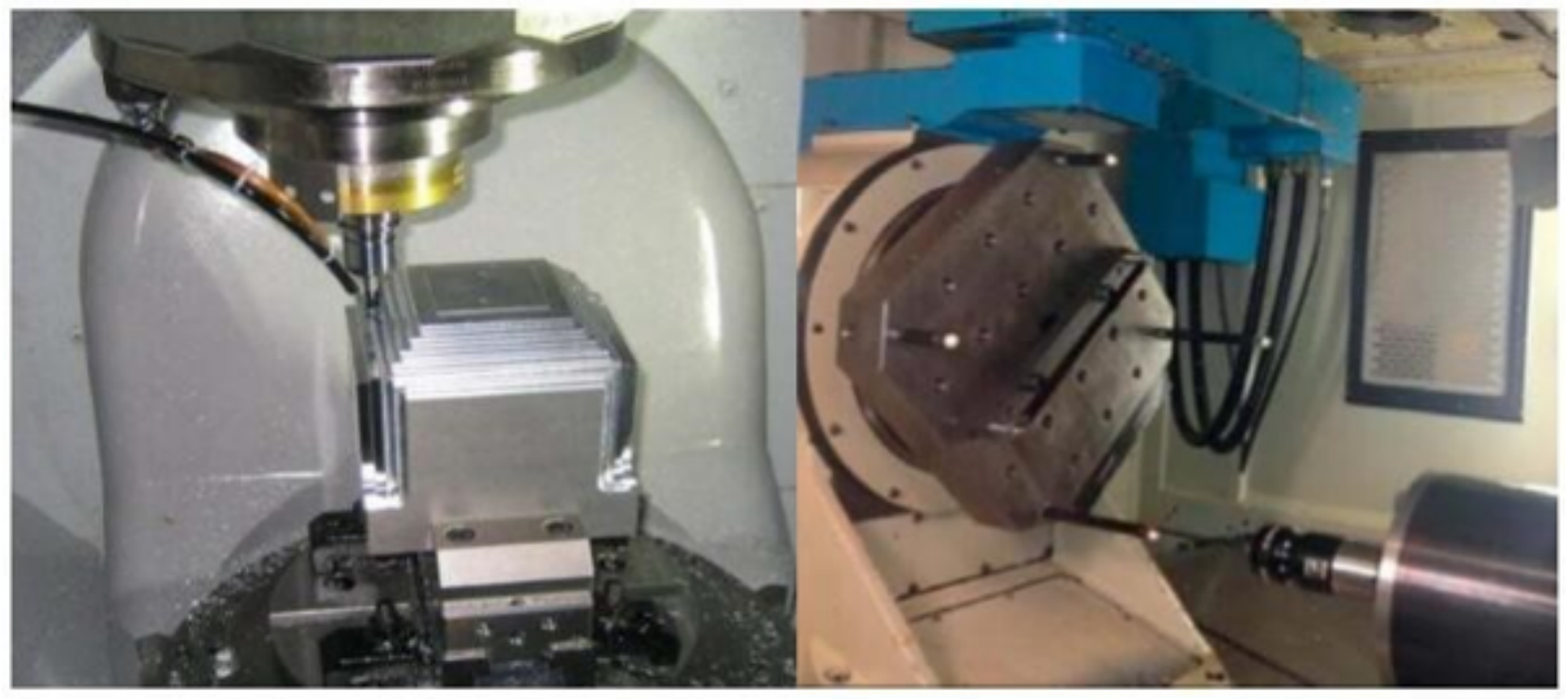

(a)

(b)

\section{Figure 1}

(a) Test method designed by Ibaraki. (b) Model designed by Erkan [9]

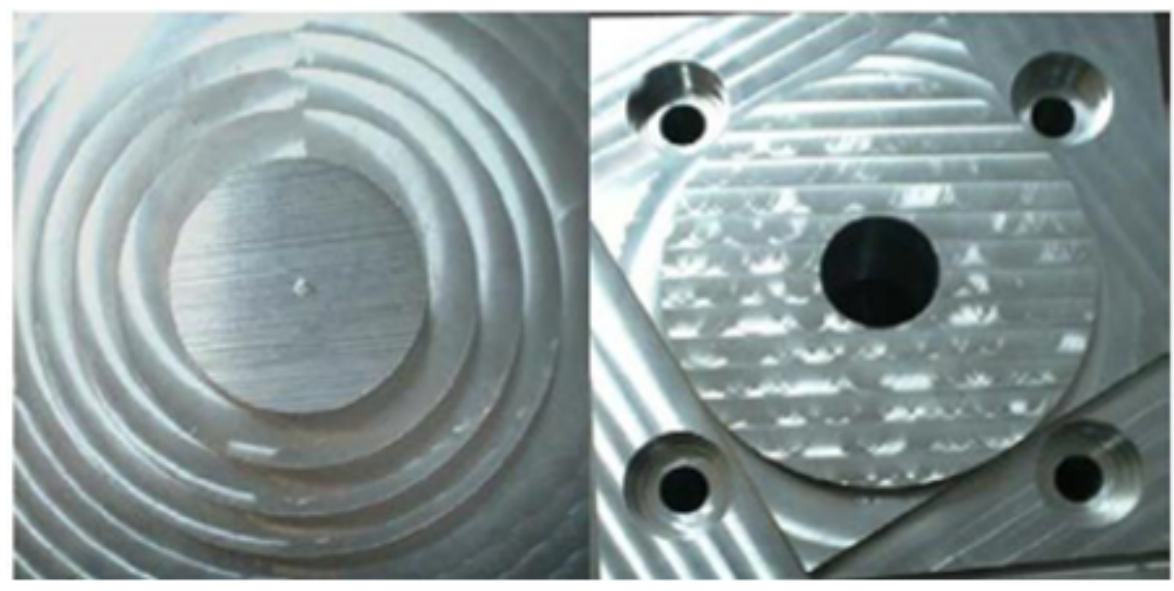

Figure 2

Stepped shaft prototype designed in this paper 


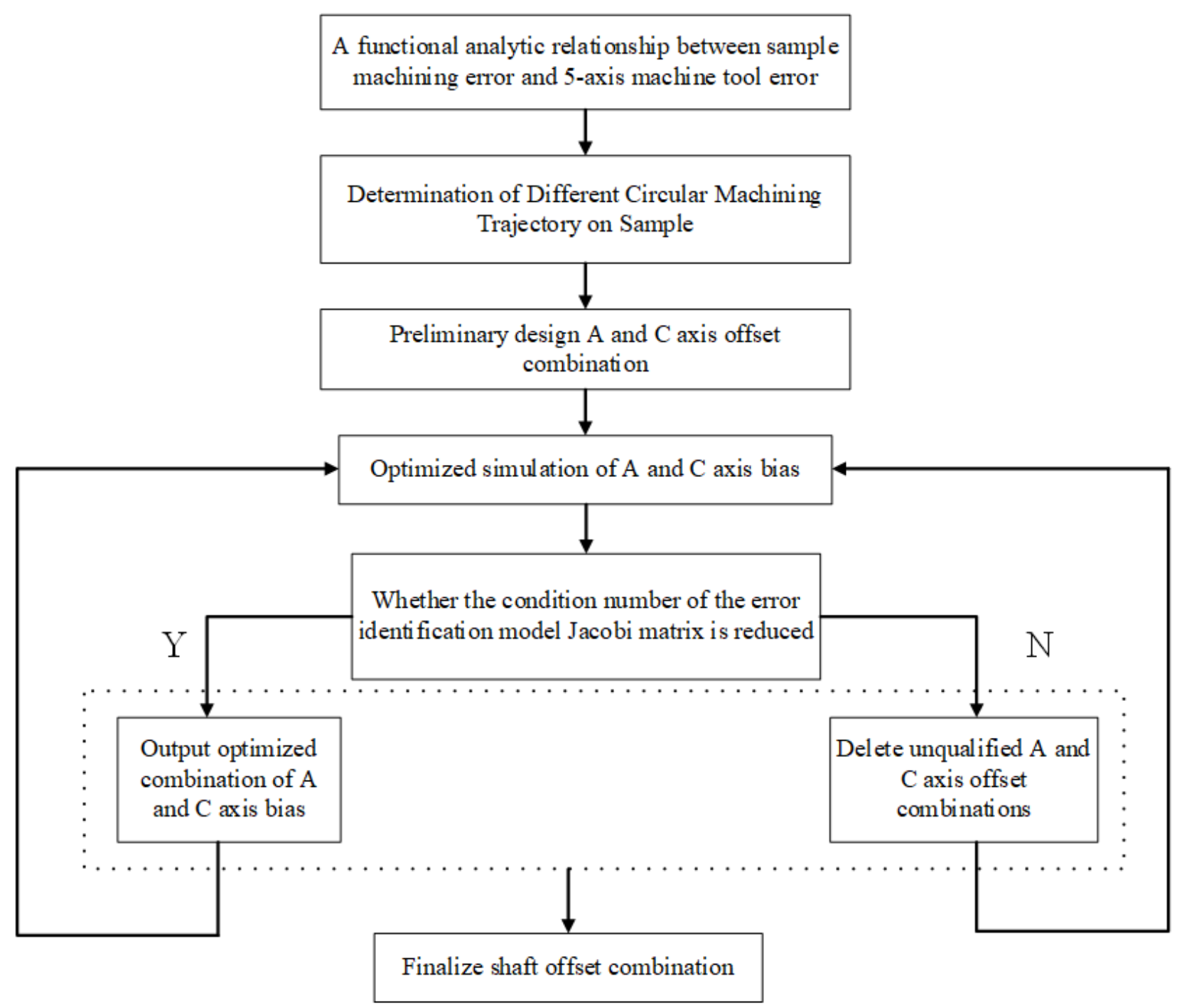

Figure 3

A axis and $\mathrm{C}$ axis offset scheme 


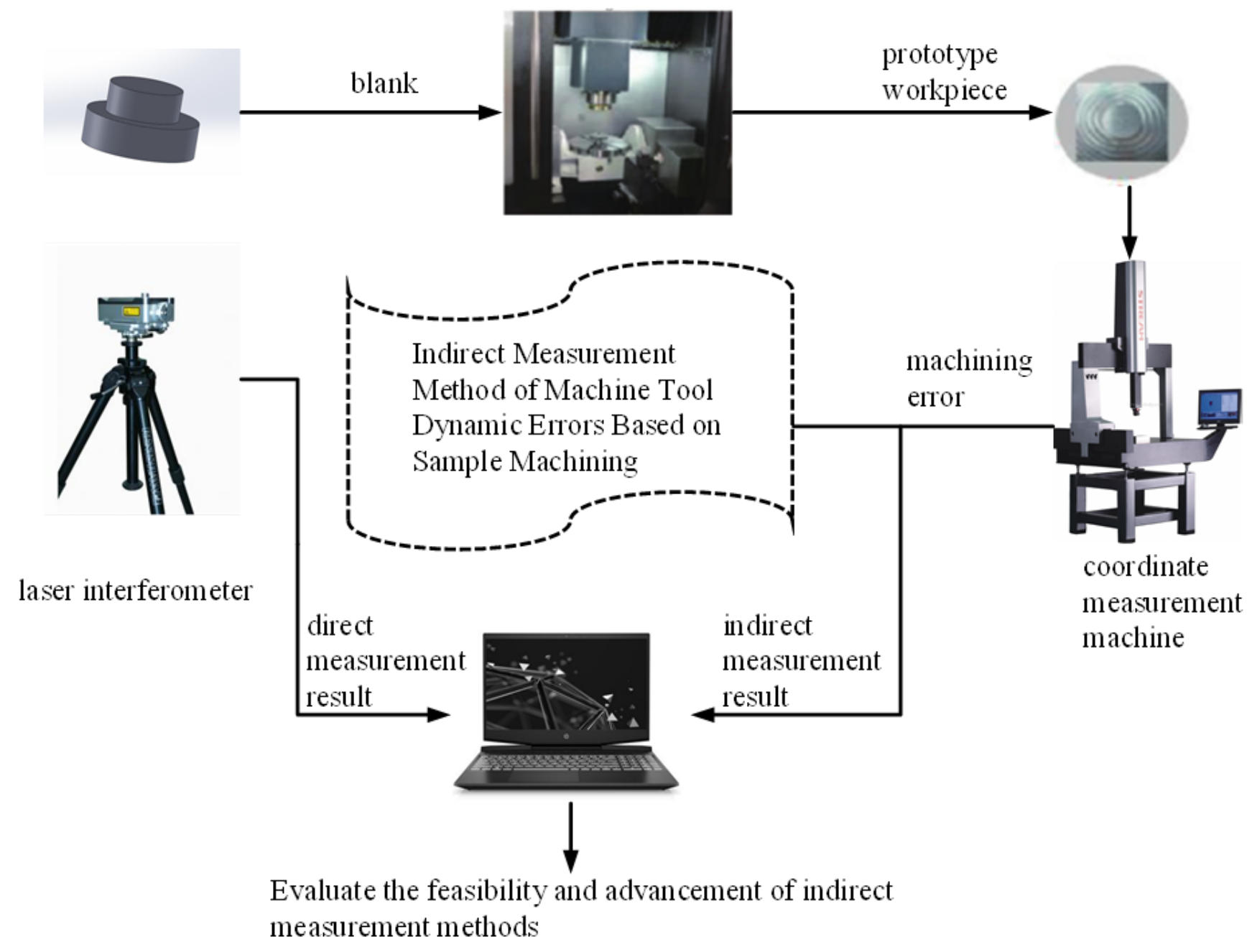

Figure 4

Five-axis $\mathrm{CNC}$ machine tool dynamic error indirect measurement scheme 


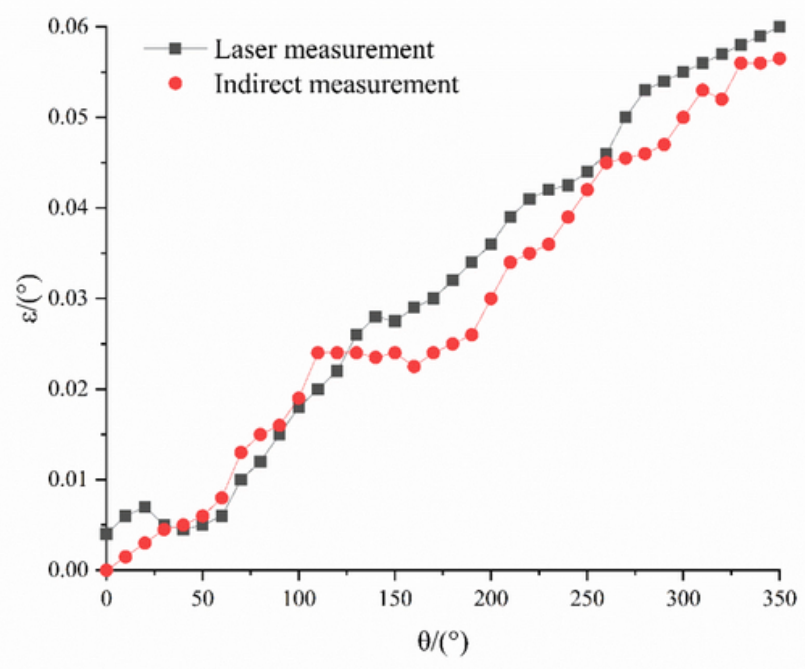

(a)

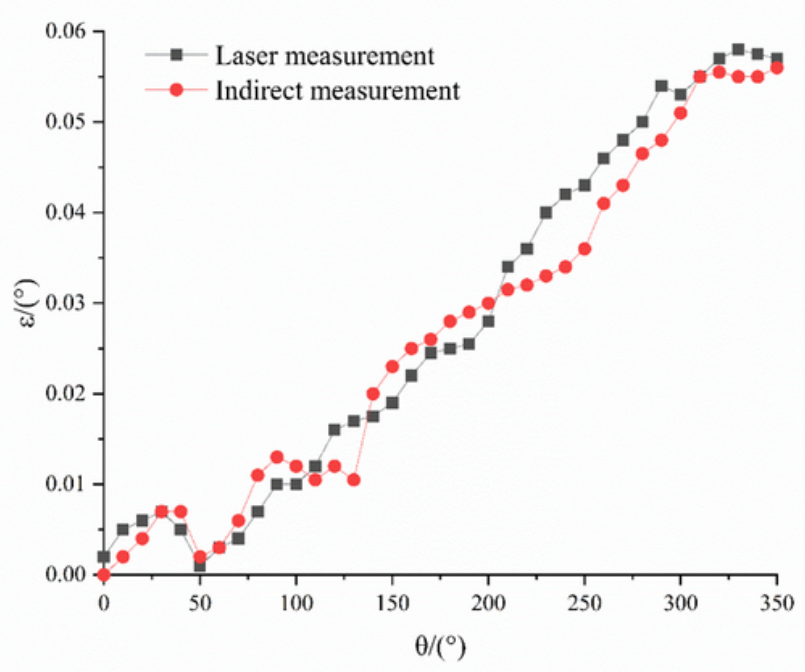

(b)

\section{Figure 5}

The identification result of the rotation axis's rotation angle positioning error. (a)Rotate A-axis (b)Rotate Baxis 


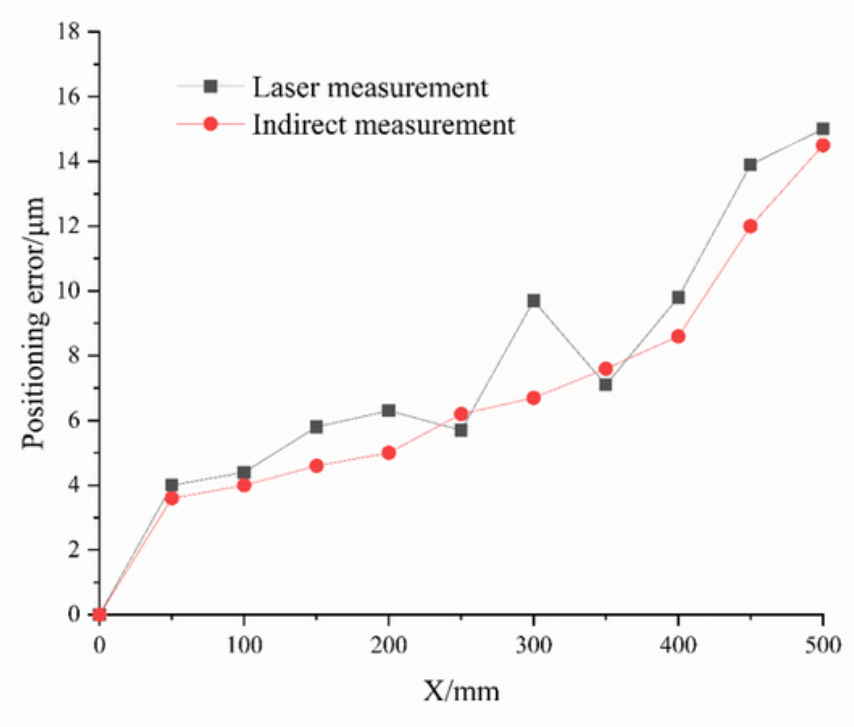

(a)

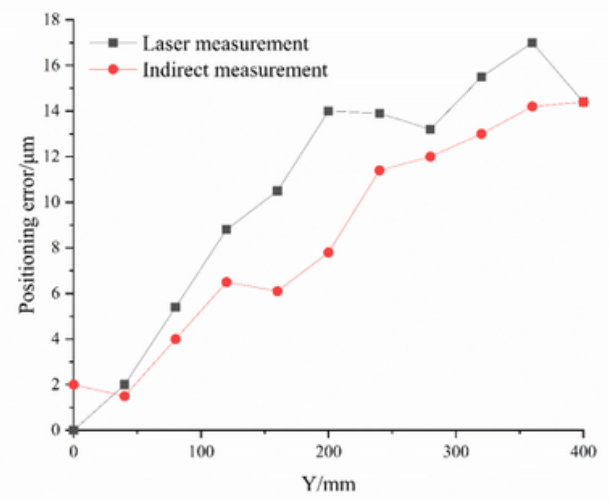

(b)

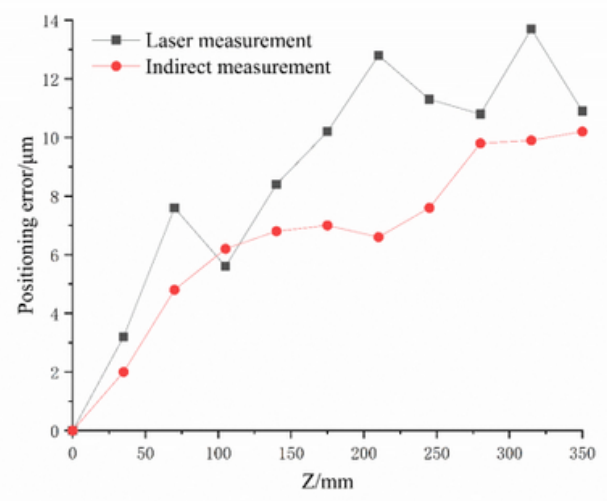

(c)

Figure 6

Positioning error identification results of (a) X-axis, (b) Y-axis and (c) Z-axis 